\title{
Role of endoscopic transnasal surgery for skull base chondrosarcoma: a retrospective analysis of 19 cases at a single institution
}

\author{
${ }^{*}$ Hirotaka Hasegawa, MD, ${ }^{1}$ Masahiro Shin, MD, PhD, ${ }^{1}$ Kenji Kondo, MD, PhD, ${ }^{2}$ \\ Shunya Hanakita, MD, PhD, ${ }^{1}$ Akitake Mukasa, MD, PhD, ${ }^{1}$ Taichi Kin, MD, PhD, ${ }^{1}$ and \\ Nobuhito Saito, MD, PhD' \\ Departments of ${ }^{1}$ Neurosurgery and ${ }^{2}$ Otorhinolaryngology, University of Tokyo Hospital, Tokyo, Japan
}

\begin{abstract}
OBJECTIVE Skull base chondrosarcoma is one of the most intractable tumors because of its aggressive biological behavior and involvement of the internal carotid artery and cranial nerves (CNs). One of the most accepted treatment strategies for skull base chondrosarcoma has been surgical removal of the tumor in conjunction with proactive extensive radiation therapy (RT) to the original tumor bed. However, the optimal strategy has not been determined. The goal of this study was to evaluate the early results of endoscopic transnasal surgery (ETS).
\end{abstract}

METHODS The authors retrospectively analyzed 19 consecutive patients who underwent ETS at their institution since 2010. Adjuvant stereotactic radiosurgery (SRS) was performed only for the small residual tumors that were not resected to avoid critical neurological complications. Histological confirmation and evaluation of the MIB-1 index was performed in all cases. The Kaplan-Meier method was used to determine the actuarial rate of tumor-free survival.

RESULTS The median tumor volume and maximal diameter were $14.5 \mathrm{~cm}^{3}$ (range $1.4-88.4 \mathrm{~cm}^{3}$ ) and $3.8 \mathrm{~cm}$ (range $1.5-6.7 \mathrm{~cm}$ ), respectively. Nine patients (47\%) had intradural extension of the tumor. Gross-total resection was achieved in $15(78.9 \%)$ of the 19 patients, without any disabling complications. In 4 patients, the surgery resulted in subtotal $(n=$ $2,11 \%)$ or partial $(n=2,11 \%)$ resection because the tumors involved critical structures, including the basilar artery or the lower CNs. These 4 patients were additionally treated with SRS. The median follow-up duration was 47, 28, and 27 months after the diagnosis, ETS, and SRS, respectively. In 1 patient with an anterior skull base chondrosarcoma, the tumor relapsed in the optic canal 1 year later and was treated with a second ETS. Favorable tumor control was achieved in all other patients. The actuarial tumor control rate was $93 \%$ at 5 years. At the final follow-up, all patients were alive and able to perform independent activities of daily living without continuous neurological sequelae.

CONCLUSIONS These preliminary results suggest that ETS can achieve sufficient radical tumor removal, resulting in comparative resection rates with fewer neurological complications to those in previous reports. Although the followup periods of these cases were relatively short, elective SRS to the small tumor remnant may be rational, achieving successful tumor control in some cases, instead of using proactive extensive RT. Thus, the addition of RT should be discussed with each patient, after due consideration of histological grading and biological behavior. To determine the efficacy of this strategy, a larger case series with a longer follow-up period is essential. However, this strategy may be able to establish evidence in the management of skull base chondrosarcoma, providing less-invasive and effective options as an initial step of treatment.

https://thejns.org/doi/abs/10.3171/2017.1.JNS162000

KEY WORDS chondrosarcoma; endoscopic surgery; Gamma Knife; transsphenoidal approach; skull base tumor; stereotactic radiosurgery; oncology

$\mathrm{S}$ KULL base chondrosarcoma is a rare tumor comprising only $0.1 \%$ of all brain tumors, which extensively invades the petroclival regions and the anterior skull base. ${ }^{7,8,38}$ In addition, chondrosarcoma often involves critical anatomical structures including the internal carotid artery (ICA) and cranial nerves (CNs), and sometimes extends into the posterior cranial fossa, penetrating the dura mater and compressing the brainstem.

Regarding the treatment strategy for chondrosarcoma, to the best of our knowledge there are only a few

ABBREVIATIONS CN = cranial nerve; EOR = extent of resection; ETS = endoscopic transnasal surgery; GKRS = Gamma Knife radiosurgery; GTR = gross-total resection; $I A C=$ internal auditory canal; ICA = internal carotid artery; $m R S=$ modified Rankin Scale; OpC = optic canal; PR = partial resection; $R T=$ radiation therapy; $S R S=$ stereotactic radiosurgery; STR = subtotal resection.

SUBMITTED August 1, 2016. ACCEPTED January 19, 2017.

INCLUDE WHEN CITING Published online July 7, 2017; DOI: 10.3171/2017.1.JNS162000.

* Drs. Hasegawa and Shin contributed equally to this work. 
TABLE 1. Detailed outcomes of ETS in each patient are shown

\begin{tabular}{|c|c|c|c|c|c|c|c|}
\hline $\begin{array}{l}\text { Case } \\
\text { No. }\end{array}$ & $\begin{array}{l}\text { Age } \\
(y r s) \\
\text { Sex }\end{array}$ & $\begin{array}{l}\text { Pathology } \\
\text { Grade }\end{array}$ & $\begin{array}{c}\text { MIB-1 } \\
\text { Index } \\
(\%)\end{array}$ & Presentation $(\mathrm{CN})$ & $\begin{array}{l}\text { Previous } \\
\text { Treatment }\end{array}$ & $\begin{array}{c}\text { Max } \\
\text { Diameter/ } \\
\text { Vol }\left(\mathrm{cm} / \mathrm{cm}^{3}\right)\end{array}$ & Tumor Location \\
\hline 1 & $56, \mathrm{M}$ & I & 1 & $\begin{array}{l}\text { Abnormal olfaction (I), visual im- } \\
\text { pairment (II), exophthalmos }\end{array}$ & & $5.5 / 54.1$ & OpC, orbit, TS, Eth, Sph, anterior cranial fossa \\
\hline 2 & $36, F$ & II (myxoid) & 5 & Diplopia (VI), tinnitus & & $4.2 / 21.1$ & Pet (+IAC), clivus, JF, HC, OcC \\
\hline 3 & $25, \mathrm{~F}$ & II & 4 & Diplopia (VI) & Transcranial & $40 / 15.7$ & Pet, clivus, JF, HC, OcC, Pha \\
\hline 4 & $77, \mathrm{~F}$ & II & 3 & Tinnitus & & $3.5 / 11.5$ & Pet (+IAC), CS, clivus, JF \\
\hline 5 & $36, \mathrm{M}$ & II & 2 & Diplopia (VI) & & $5.2 / 28.3$ & Pet (+IAC), bilateral CS, clivus, JF, Sph, CPA \\
\hline 6 & $29, \mathrm{M}$ & II & 1 & Diplopia (VI) & Transcranial & $3.0 / 9.6$ & CS, sella turcica, suprasellar region, clivus \\
\hline 7 & $39, \mathrm{M}$ & II & 3 & Diplopia (VI), ataxia & $\begin{array}{l}\text { Transcranial } \\
\quad \times 3\end{array}$ & $6.7 / 88.4$ & $\begin{array}{l}\text { Pet (+IAC), bilateral CS, clivus, JF, Sph, pons, } \\
\text { medulla }\end{array}$ \\
\hline 8 & $48, M$ & I & 3 & Diplopia (VI), CN XII palsy & & $4.6 / 14.5$ & Pet (+IAC), CS, clivus, JF, HC, OcC \\
\hline 9 & $36, \mathrm{~F}$ & II & 1 & Diplopia (III/VI), facial pain (V) & Transcranial & $3.0 / 9.4$ & CS, clivus, Pet, JF, HC \\
\hline 10 & $49, F$ & II & 5 & Diplopia (VI) & & $3.7 / 11.8$ & Pet $(+\mid A C), C S$, clivus \\
\hline 11 & $41, \mathrm{M}$ & II & 1 & Diplopia (VI) & & $3.8 / 21.3$ & CS, clivus, Pet, JF \\
\hline 12 & $32, \mathrm{M}$ & II & 1 & Diplopia (VI) & Transcranial & $4.1 / 16.7$ & Pet (+IAC), JF, CS, clivus, middle cranial fossa, CPA \\
\hline 13 & $82, \mathrm{~F}$ & II & 3 & Visual impairment (II) & Endonasal & $5.0 / 48.3$ & OpC, orbit, TS, Eth, Sph, anterior cranial fossa \\
\hline 14 & $33, \mathrm{~F}$ & II & 1 & Ataxia, gait disturbance & & $2.6 / 5.2$ & $\begin{array}{l}\text { CS, clivus, Pet (+IAC), JF, HC, middle cranial fossa, } \\
\text { CPA }\end{array}$ \\
\hline 15 & $31, \mathrm{M}$ & III & 20 & Epistaxis, headache & $\begin{array}{l}\text { Biopsy + Cy- } \\
\text { berKnife }\end{array}$ & $3.7 / 17.0$ & $\begin{array}{l}\text { OpC, Eth, Sph, TS, sella turcica, CS, clivus, medial } \\
\text { temporal lobe }\end{array}$ \\
\hline 16 & $39, \mathrm{~F}$ & II & 1 & Diplopia (VI) & Transcranial & $1.5 / 1.4$ & $\begin{array}{l}\text { CS, clivus, Sph, Pet, middle cranial fossa, medial } \\
\text { temporal lobe }\end{array}$ \\
\hline 17 & $30, M$ & II & $2-3$ & Diplopia (VI) & & $4.1 / 8.2$ & CS, clivus, Pet, JF, pons \\
\hline 18 & $43, \mathrm{M}$ & II & 1 & Diplopia (VI) & & $2.6 / 6.8$ & Pet, clivus, JF, CPA \\
\hline 19 & $66, F$ & II & 1 & Headache & & $3.1 / 9.4$ & Sph, clivus, Pet, JF, HC, pons \\
\hline
\end{tabular}

$\mathrm{CPA}=$ cerebellopontine angle; $\mathrm{CS}=$ cavernous sinus; Eth = ethmoid sinus; $\mathrm{HC}=$ hypoglossal canal; $\mathrm{JF}=$ jugular foramen; OcC = occipital condyle; Pet = petrous bone; Pha = pharynx; $\mathrm{Sph}=$ sphenoid sinus; $\mathrm{TS}$ = tuberculum sellae .

reports of using the transcranial approach to aim for maximum tumor resection followed by proactive extensive radiation therapy (RT), including proton-beam radiation., ${ }^{7,51,54}$ In this strategy, however, transcranial resection for the deeply seated tumor itself carries certain risks of neurological complications as well as a high degree of invasiveness even with modern skull base techniques, which proportionally increase with resection rate. Additionally, proactive high-dose RT to the original tumor bed can reduce the risk of recurrence, whereas it may simultaneously bring some undesirable adverse events.

With the recent advent of endoscopic technology in the field of neurosurgery, a wide range of skull base regions

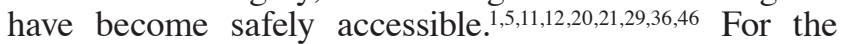
treatment of skull base chondrosarcoma, there are a few reports about the outcomes of endoscopic endonasal surgeries, which commonly achieved sufficient tumor resection with acceptable neurological complications. ${ }^{42,44,66}$ In this study, we present our recent experience of endoscopic transnasal surgery (ETS) for skull base chondrosarcoma. Based on our surgical outcomes, we discuss the efficacy of ETS and the role of stereotactic radiosurgery (SRS) in this era of state-of-the-art "less invasive" skull base surgery.

\section{Methods \\ Study Population}

Since 2010, 21 cases of chondrosarcomas were referred to our institution; 2 (9.5\%) were treated with transcranial approaches, and 19 (90.5\%) were treated with ETS. In our policy, tumors mainly extending to the lateral parts of the CNs (such as superior and lateral aspects of the optic canal $[\mathrm{OpC}]$ and the orbit, or the mastoid air cells outside the internal auditory canals [IACs]) are easily approached from the outside and are considered good candidates for transcranial approaches. In contrast, for tumors extensively involving the paramedian regions or the inferior portion of the petrous apex such as the clivus, sphenoid sinus, nasopharyngeal region, bilateral petrous apex, or jugular fossa, it is more reasonable to approach from inside; these are good candidates for ETS.

We retrospectively reviewed the medical records of these 19 consecutive patients who underwent ETS for chondrosarcoma. Ten patients $(53 \%)$ were initially treated in our hospital, and the other 9 patients (47\%) were referred to us after the failure of various treatments in previous hospitals (transcranial resection in 6 patients, transsphenoidal surgery in 3, and hypofractionated RT in 1). The di- 
TABLE 2. Detailed outcomes of ETS in each patient

\begin{tabular}{|c|c|c|c|c|c|c|c|c|}
\hline $\begin{array}{l}\text { Case } \\
\text { No. }\end{array}$ & $\begin{array}{l}\text { Pathology } \\
\text { Grade }\end{array}$ & EOR & $\begin{array}{c}\text { Time Btwn Diagnosis \& } \\
\text { ETS (mos) }\end{array}$ & Complication & $\begin{array}{l}\text { Follow-Up } \\
\text { (mos) }^{*}\end{array}$ & $\begin{array}{l}\text { GKRS } \\
(\operatorname{mos})^{*}\end{array}$ & $\begin{array}{l}\text { Recurrence } \\
\text { (mos) }^{*}\end{array}$ & $\begin{array}{l}\text { Final mRS } \\
\text { Score }\end{array}$ \\
\hline 1 & I & GTR & 1 & - & 62 & - & No & 0 \\
\hline 2 & II (myxoid) & GTR & 17 & CSF leak & 58 & - & No & 0 \\
\hline 3 & II & GTR & 3 & - & 36 & - & No & 1 \\
\hline 4 & II & GTR & 20 & Transient abducens palsy & 39 & - & No & 0 \\
\hline 5 & II & STR & 4 & - & 36 & Yes (3) & No & 0 \\
\hline 6 & II & PR & 9 & - & 36 & Yes (5) & No & 0 \\
\hline 7 & II & GTR & 47 & Transient abducens palsy & 38 & - & No & 0 \\
\hline 8 & I & GTR & 2 & - & 30 & - & No & 0 \\
\hline 9 & II & STR & 4 & - & 30 & Yes (8) & No & 1 \\
\hline 10 & II & GTR & 4 & Transient abducens palsy & 28 & - & No & 0 \\
\hline 11 & II & GTR & 32 & - & 15 & - & No & 0 \\
\hline 12 & II & GTR & 164 & - & 25 & - & No & 0 \\
\hline 13 & II & GTR & 89 & - & 16 & - & Yes (12) & 2 \\
\hline 14 & II & GTR & 8 & - & 19 & - & No & 0 \\
\hline 15 & III & GTR & 54 & - & 15 & - & No & 0 \\
\hline 16 & II & GTR & 55 & - & 16 & - & No & 1 \\
\hline 17 & II & PR & 2 & - & 15 & Yes (4) & No & 0 \\
\hline 18 & II & GTR & 8 & - & 7 & - & No & 1 \\
\hline 19 & II & GTR & 4 & - & 7 & - & No & 1 \\
\hline
\end{tabular}

* After ETS.

agnosis was histologically verified in all the patients, and the MIB-1 index was assessed.

\section{Treatment Strategy}

Since the introduction of the endoscopic approach for skull base chondrosarcomas, we have consistently applied the following strategy. First we recommend ETS, aiming for maximum resection. Second, if there is a remnant tumor component, we recommend adjuvant SRS 3-6 months after surgery. At SRS, only the residual tumor is selectively irradiated, and the patient is then followed up with periodic radiological imaging. And third, after gross-total resection (GTR), the patient is simply followed up with periodic radiological checkups. If there is a recurrence, resection or SRS is recommended depending on the tumor location. We usually recommend resection for a recurrence close to the anterior visual pathway or after high-dose RT.

\section{Surgical Techniques}

Details of our surgical approach in ETS have been described in previous publications. ${ }^{55-57}$ Briefly, the surgical navigation system (StealthStation Navigation, Medtronic Japan) and monitoring of $\mathrm{CN}$ function (electromyography of extraocular muscles, facial muscles, pharyngeal musculature with the special tracheal tube, and the tongue, as well as auditory brainstem response audiometry) were set to avoid CN injuries (Neuromaster, Nihon Kohden). Endoscopes $4 \mathrm{~mm}$ in diameter with $0^{\circ}, 30^{\circ}$, and $70^{\circ}$ lenses were used (175- to 180-mm-long rigid scopes; Karl Storz Endoscopy Japan), which were stabilized in the surgical field with a robotic holding device (Point Setter, Mitaka Kohki). The tumors were approached via the transsphenoidal route under the $0^{\circ}$ endoscope, and those extending laterally to the petrous apex were resected through the retrocarotid space under the angled endoscopes. ${ }^{56}$ The tumors located in the lower clivus, the craniovertebral junction, and the nasopharynx were approached through the upper pharynx.${ }^{55}$ For those located in the parapharyngeal space or the pterygopalatine fossa, the transpterygoid approach or the transmaxillary approach was added as necessary. We directly approached tumors located mainly in the anterior skull base region through the ethmoidal sinus. ${ }^{57}$ When the tumor was strongly adherent to critical anatomical regions such as the brainstem and the basilar artery or involved the adjacent $\mathrm{CNs}$, resection remained maximal but judicious volume reduction and Gamma Knife radiosurgery (GKRS) was planned for the site of the residual tumors 3-6 months after surgery.

Every patient underwent endoscopic examination by an otolaryngologist at 1 week postoperatively. Patients visited our outpatient clinic at 1 month postoperatively for neurological evaluation and a second rhinological checkup.

\section{Evaluation of Surgical Outcomes}

All radiological images, including CT and MR images, were reviewed independently by 2 radiologists and 1 follow-up neurosurgeon, and the volumetric measurement was performed using GammaPlan software (Elekta Instruments, Inc.). Gross-total resection (GTR) was defined as disappearance of the tumor on postoperative MRI with contrast medium. Subtotal resection (STR) and partial resection (PR) were defined as $\geq 90 \%$ and $<90 \%$ resection, respectively. ${ }^{19}$

Follow-up MRI was performed within 3 days after 


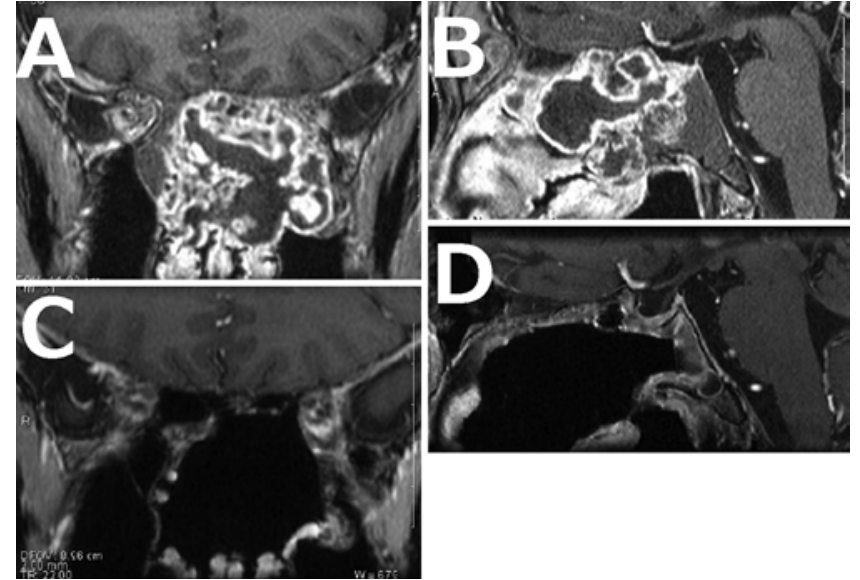

FIG. 1. Case 1. Images obtained in a 56-year-old man who presented with abnormal olfaction, impaired vision of the left eye with exophthalmos, and diplopia. MRI revealed a large mass lesion located in the anterior cranial base and nasal cavity, compressing the left orbit ( $A$ and B). We performed an endoscopic endonasal approach and the tumor was successfully removed. After surgery, he transiently complained of mild facial numbness, but his vision symptoms remarkably improved. The histological diagnosis was chondrosarcoma Grade I. The patient was followed up with periodic MRI without prophylactic radiation. MRI obtained at the last follow-up evaluation, 62 months after surgery, did not show any sign of recurrence ( $C$ and $D)$.

surgery (short-term) to determine the extent of tumor removal, and then 3 and 6 months later. Postoperative neurological status was assessed at discharge and at 1,3, and 6 months or later. The modified Rankin Scale (mRS) result was assessed based on the patient's condition at the final outpatient visit, and classified as excellent (mRS score of $0-1$ ), favorable (mRS score of 2), moderately impaired (mRS score of 3), or disabled (mRS score of 4-5). ${ }^{62}$

\section{Results}

The baseline characteristics of the patients and the detailed tumor locations are summarized in Table 1. Briefly, 17 patients $(89 \%)$ had petroclival chondrosarcomas, and the other 2 patients (11\%) had anterior skull base chondrosarcomas. Intradural extension was observed in 9 patients $(47 \%)$. The median tumor volume and maximal diameter were $14.5 \mathrm{~cm}^{3}$ (range $1.4-88.4 \mathrm{~cm}^{3}$ ) and $3.8 \mathrm{~cm}$ (range $1.5-6.7 \mathrm{~cm})$, respectively.

The detailed outcomes of each patient are summarized in Table 2. Among 19 tumors, 2 (10.5\%) were histologically diagnosed as Grade I, $16(84.2 \%)$ as Grade II, and $1(5.2 \%)$ as Grade III. GTR of the tumor was achieved in 15 patients $(78.9 \%)$. We abandoned attempts at GTR in 4 patients during surgery, balancing the potential risks of small but possibly serious complications with those of additional SRS. Among these 4 patients, the lower CNs were involved in calcified lesions at the jugular fossa in 2 patients $(10.5 \%)$, which resulted in STR. In the other 2 patients $(10.5 \%)$, solid tumor components engulfed the basilar artery or the ICA, which remained partially resected. Thus, resection rates were affected not by the intradural extension but by involvement of CNs or critical arteries in the calcified lesions.
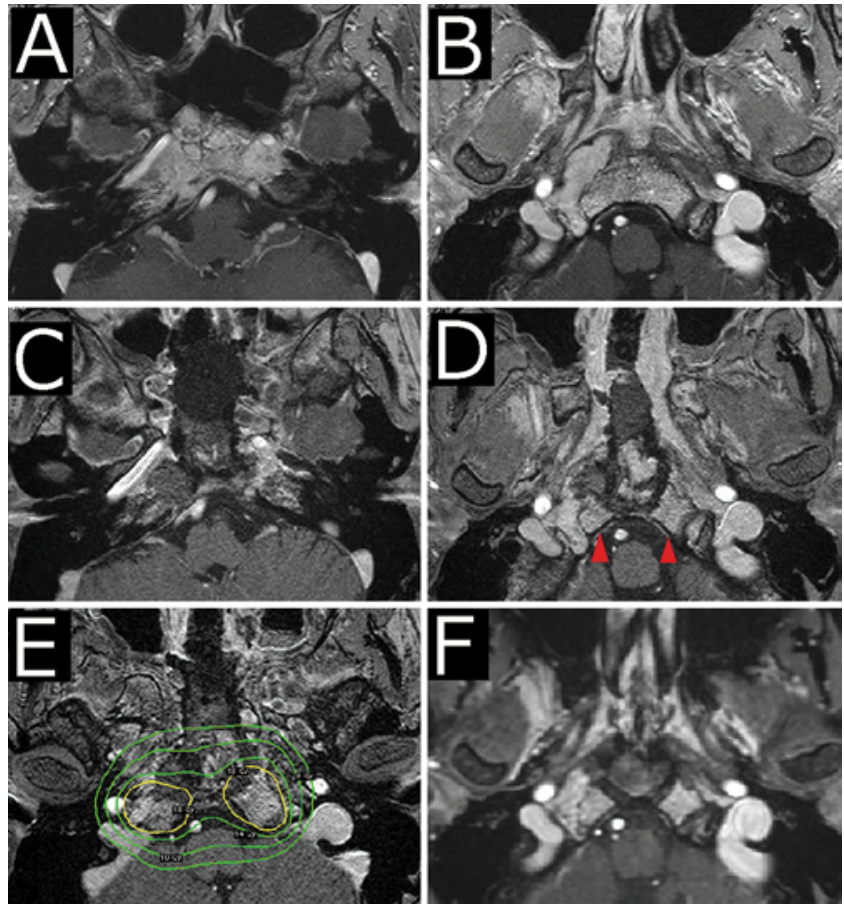

FIG. 2. Case 5. A 36-year-old man presented with diplopia caused by bilateral abducens nerve palsy. His MRI disclosed a tumor located in the petroclival region that extended to the bilateral petrooccipital fissures and the jugular tubercle (A and B). At resection, the tumor was almost completely removed (C), but there was a small amount of residual tumor at the jugular tubercle (D, arrowheads). His symptoms improved after surgery, and 8 months later, he underwent GKRS for the small tumor remnant at the bilateral jugular tubercle. The yellow lines represent an 18-Gy isodose line of SRS, covering the target, and the green lines indicate 8, 10, and $14 \mathrm{~Gy}(\mathrm{E})$. The follow-up MRI obtained 32 months after GKRS revealed successful tumor control $(F)$. Figure is available in color online only.

The 4 patients (21\%) with tumor remnants underwent GKS at an interval of 3-8 months (median 5 months) after ETS. The prescribed radiosurgical dose ranged from 16 to $18 \mathrm{~Gy}$ (median $18 \mathrm{~Gy}$ ) to the tumor margin and the targeting tumor volume ranged from 1.8 to $13.8 \mathrm{~cm}^{3}$ (median $\left.6.6 \mathrm{~cm}^{3}\right)$.

In our series, the transcranial approach and endoscopic transnasal approach were each used for the treatment of distinct types of skull base chondrosarcomas. Thus, previous transcranial surgeries did not affect the results of later ETSs. Representative cases are shown in Figs. 1-4.

\section{Tumor Control}

The patients were followed up for a median of 47 months (range 11-189 months) after the initial diagnosis and 28 months (range 7-62 months) after ETS. In 18 patients, there was no sign of recurrence on clinical follow-up examinations and radiological studies. In 1 patient (Case 13), a small tumor component rapidly recurred in the $\mathrm{OpC}$ 1 year after the initial ETS, and a second resection was performed without complications.

The overall actuarial tumor control rates were $92.9 \%$ at 3 and 5 years (Fig. 5), whereas tumor control was essentially achieved in all patients at the final analysis. 


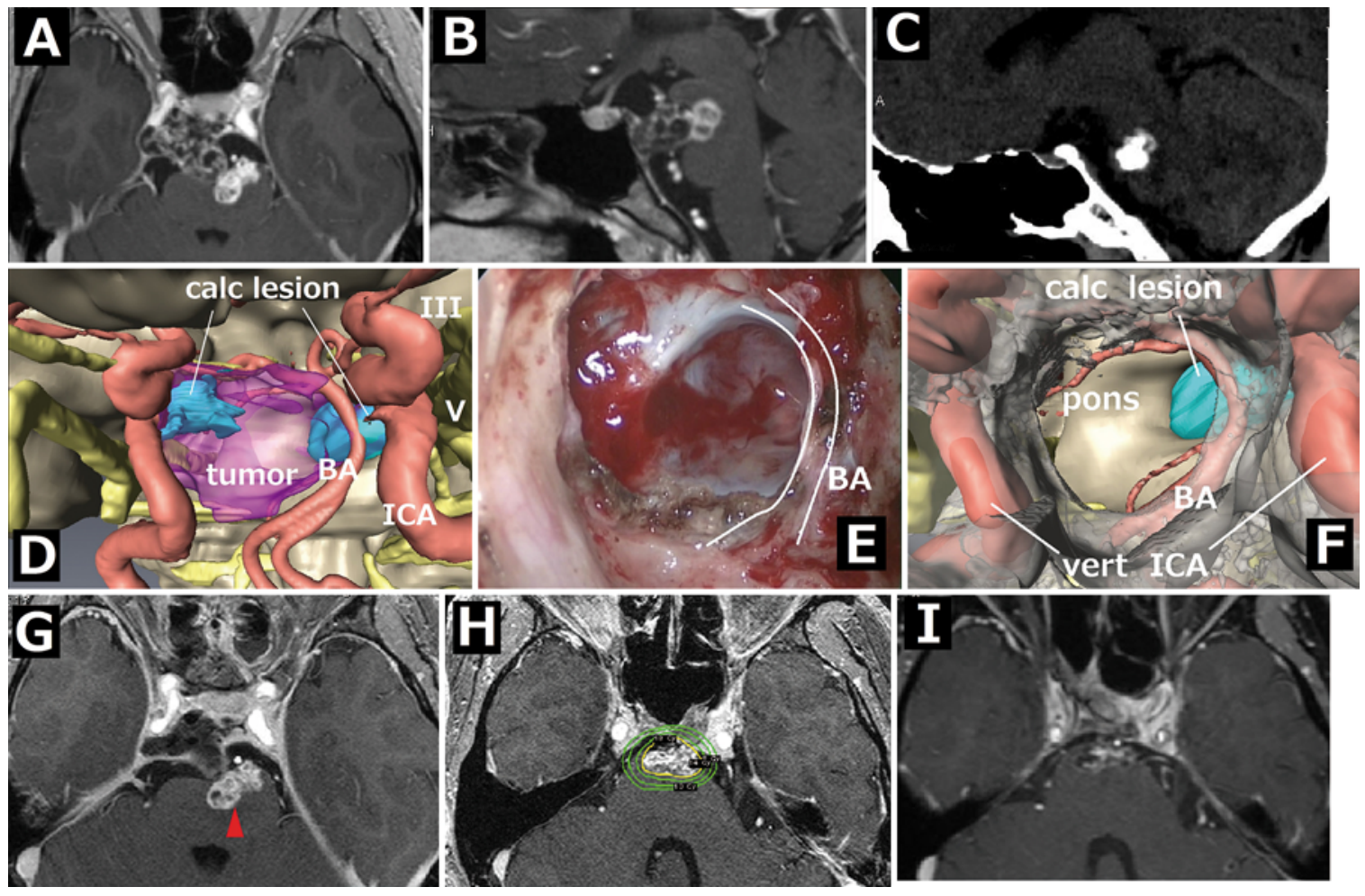

FIG. 3. Case 17. A 30-year-old man presented with diplopia caused by mild abducens nerve palsy. His MRI disclosed a tumor located in the petroclival region, which extended to the posterior cranial fossa, strongly compressing the brainstem with involvement of the basilar artery (BA; A and B). Notably, the tumor contained two prominent calcified (calc) parts, and one of them was embedded in the pons (C). A 3D computer graphics model was created for the purpose of surgical simulation (D and F). At resection, the calcified tumor component strongly adhered to the pontine surface, involving the BA (E). To avoid injury of the brainstem and BA, we intentionally left this calcified lesion. Postoperative MRI showed a small residual tumor in the left pons (G, arrowhead). His symptoms rapidly improved after surgery, and GKRS was performed for the residual tumor 4 months later. The yellow lines represent an 18-Gy isodose line of SRS, covering the target, and the green lines indicate 8, 10, and 14 Gy (H). Follow-up MRI obtained 12 months after GKRS revealed successful tumor control (I). vert ICA = vertical portion of the ICA; III = oculomotor nerve; $V=$ trigeminal nerve. Figure is available in color online only.

\section{Complications}

In 1 patient (Case $4 ; 6 \%)$, transient abducens nerve palsy newly developed after ETS, which completely resolved in 2 weeks. Two patients (11\%) presented with transient worsening of existing abducens nerve palsy. In these patients, the symptoms completely resolved within 3 and 6 months (Cases 10 and 7, respectively). One patient (Case 2; 6\%) showed delayed CSF rhinorrhea 1 week after surgery, which required an additional surgical repair. In this case, CSF leakage had not been apparent during surgery, but suddenly occurred 1 week later. At the surgical repair, no dural defect was evident, but continuous oozing of CSF was found around the internal auditory meatus. In the 4 patients who underwent GKS, none showed radiationinduced neurological complications during follow-up. At the last follow-up periods, excellent functional outcomes were achieved in all except for 1 patient (Case 13) who had moderate impairment due to senility (mRS score of 2 , unrelated to the treatment or the primary disease).

\section{Discussion}

In the present study we conducted a retrospective analysis of 19 patients with skull base chondrosarcoma to clarify the efficacy of endoscopic surgery and the role of adjuvant radiation. This is one of the largest series of skull base chondrosarcomas treated at a single institution under a consistent therapeutic strategy. In our strategy, after initial radical treatment (GTR or STR/PR + SRS for small tumor remnants), we consistently maintained a policy of observation with periodic MRI, without proactive extensive RT covering the original tumor bed. The actuarial local tumor control rate was $93 \%$ at 5 years and all tumors were successfully controlled without any persistent neurological complications at the final analysis. Our results indicate that endoscopic skull base surgery can achieve satisfactory results, i.e., comparable rates of total or subtotal resections with fewer neurological complications compared to previous series using transcranial approaches (Table 3). ${ }^{8,10,25,51,53,54,61}$

\section{Role of ETS for Chondrosarcoma}

After the introduction of endoscopic technology to the neurosurgical fields, safe surgical approaches to the paramedian skull base became feasible, and the role of surgery dramatically changed for a variety of skull base lesions. ${ }^{1,5}$. $11-13,21,36,55,57,59,60$ Recently, reports on the endoscopic approach for petrous apex lesions have been gradually increasing, $15,22,28,33,35,36,41,47,56,59,65$ whereas there are still only 

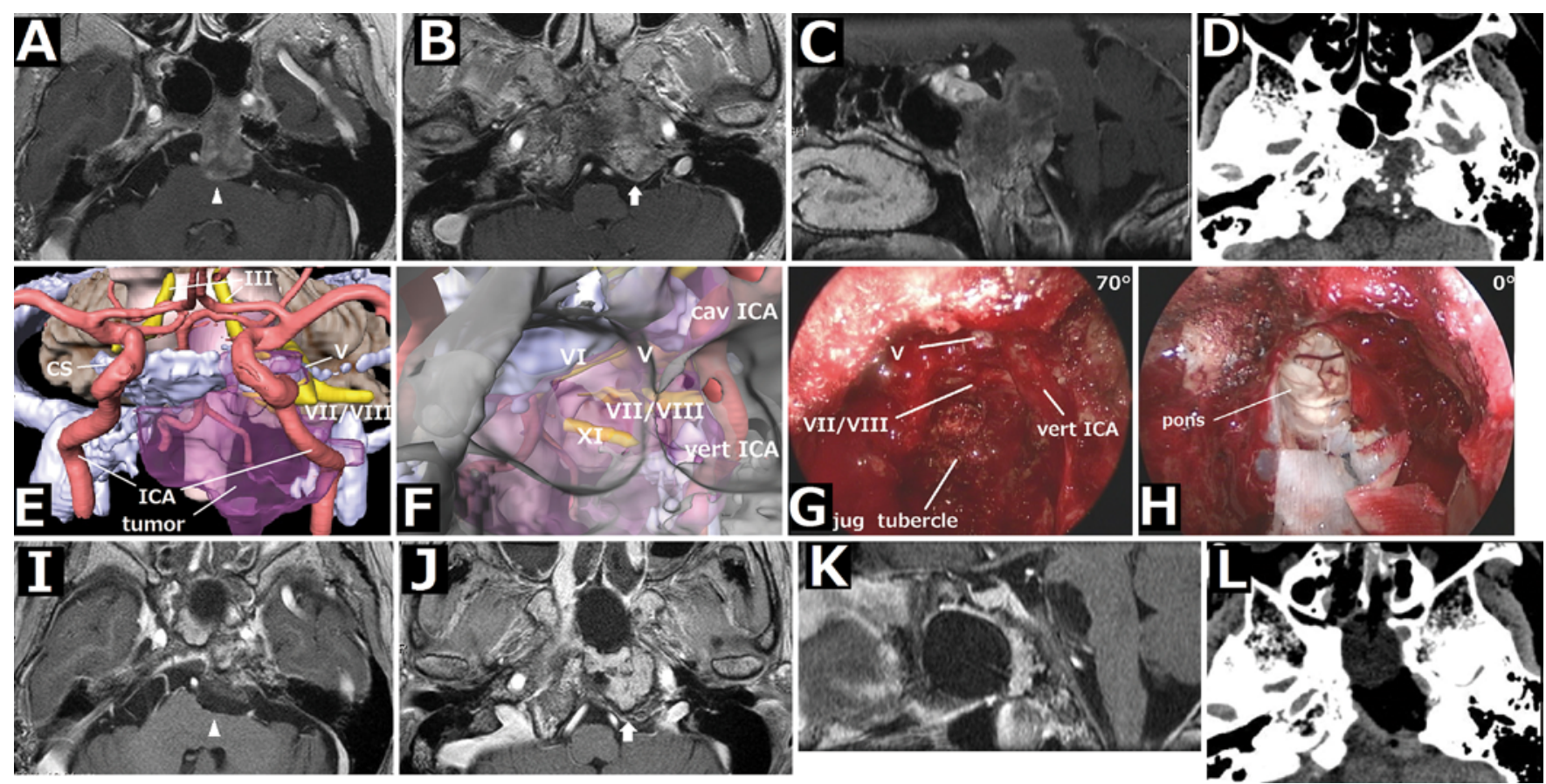

FIG. 4. Case 19. A petroclival tumor was found in a 66-year-old woman with headache. Preoperative MRI and CT (A-D) disclosed a mass lesion in the petroclival area extending into the parapharyngeal space and left jugular (jug) tubercle (arrow), penetrating the clival dura mater and strongly compressing the pons (arrowhead). A 3D computer graphics model was created for the purpose of surgical simulation (E and $\mathbf{F})$. The tumor was completely removed through the retro-carotid window $(\mathbf{G}$ and $\mathbf{H})$. Postoperative MRI (I-K) showed complete removal of the tumor through an adequately wide surgical corridor ( $\mathbf{L})$. The arrowhead (I) and arrow $(\mathrm{J})$ represent the region where the tumor had invaded before surgery and was successfully removed. cav ICA = cavernous portion of the ICA; VI = abducens nerve; VII/VIII = IAC. Figure is available in color online only.

a few reports on the outcomes of skull base chondrosarcoma, in which investigators commonly applied proactive RT regardless of the extent of resection (EOR; Table 3). ${ }^{23,42,44,66}$ Thus, it is difficult to definitively determine the efficacy of endoscopic surgery for skull base chondrosarcomas to date.

Compared with transcranial skull base surgery, ETS has some benefits based on the anatomical nature of chondrosarcoma. Although its histogenetic origin remains a matter of debate, it is postulated that chondrosarcoma is

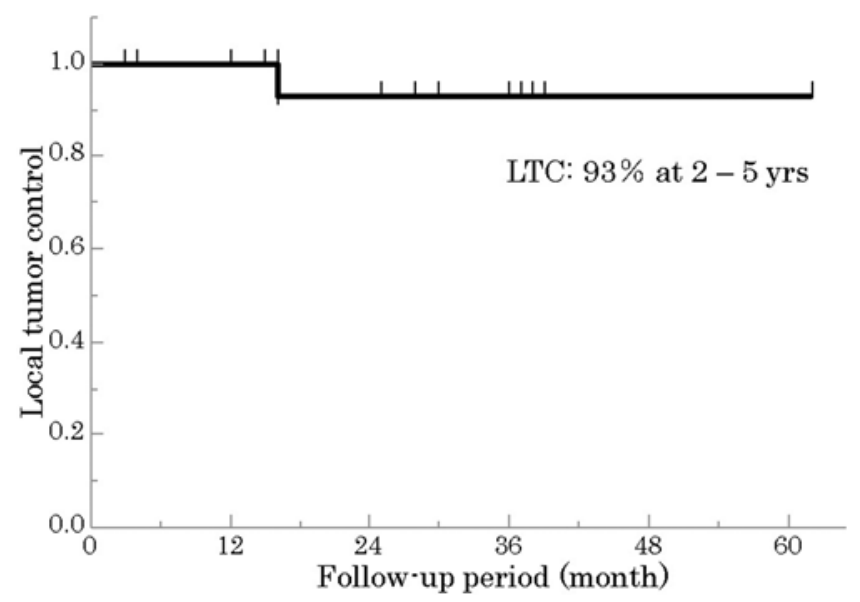

FIG. 5. The Kaplan-Meier curve for local tumor control (LTC) is shown. a neoplasm of mesenchymal precursor cells destined to undergo chondrocytic cell differentiation, $2,17,18$ and the intracranial foci of these precursor cells are located at the synchondroses that present in the midline part of the skull base (sphenooccipital, interoccipital, petrooccipital, intersphenoidal, and sphenoethmoidal synchondrosis). Indeed, almost all the skull base chondrosarcomas are located at the paramedian skull base, displacing adjacent $\mathrm{CNs}$ laterally. Therefore, the direct surgical approach from the nasal corridor is quite reasonable (Fig. 6). In contrast, in the transcranial approaches, significant parts of surgical procedures are performed through narrow spaces between involved $\mathrm{CNs}$, and it is very difficult to balance the resection rate and the risk of neurological complications. We believe that these characteristics peculiar to the approach routes resulted in the favorable rate of GTR as well as the low rates of $\mathrm{CN}$-related complications in ETS, as noted in this study and previous reports (Table 3 ).

However, there are some possible drawbacks to ETS. First, its surgical corridor is a long and narrow keyhole shape, which may impose some extent of difficulty on surgeons for manipulation. The second problem is the lateral limit of the surgical corridor. Basically, ETS uses the space between bilateral ICAs to approach the paramedian skull base, which means that the ICA can become an obstacle when treating tumors with extremely lateral extensions behind the ICA. To overcome these issues, we frequently used oblique-viewing endoscopes $\left(30^{\circ}\right.$ or $\left.70^{\circ}\right)$, which provide an adequate surgical view for laterally extending tumors with use of variously curved surgical devices. 


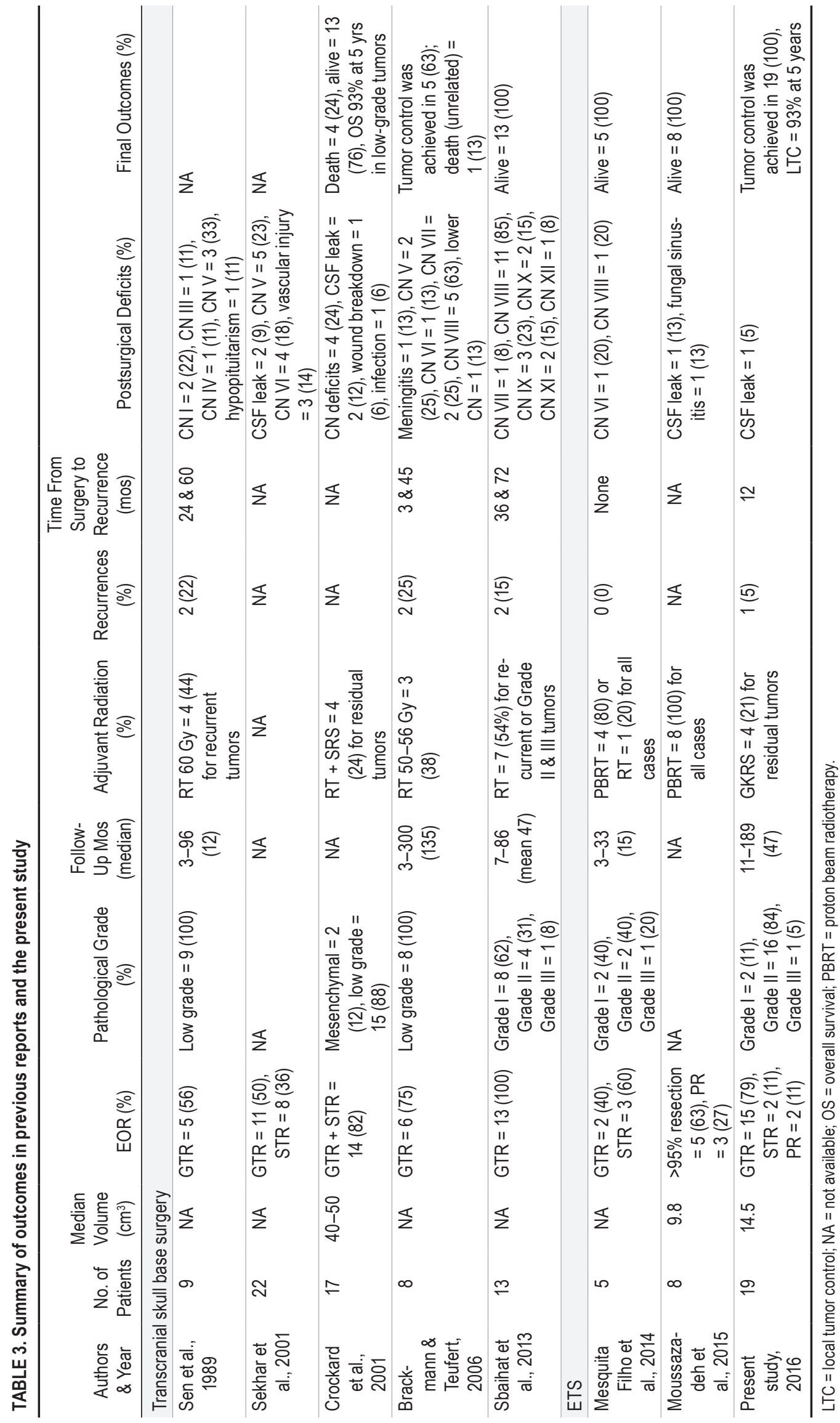




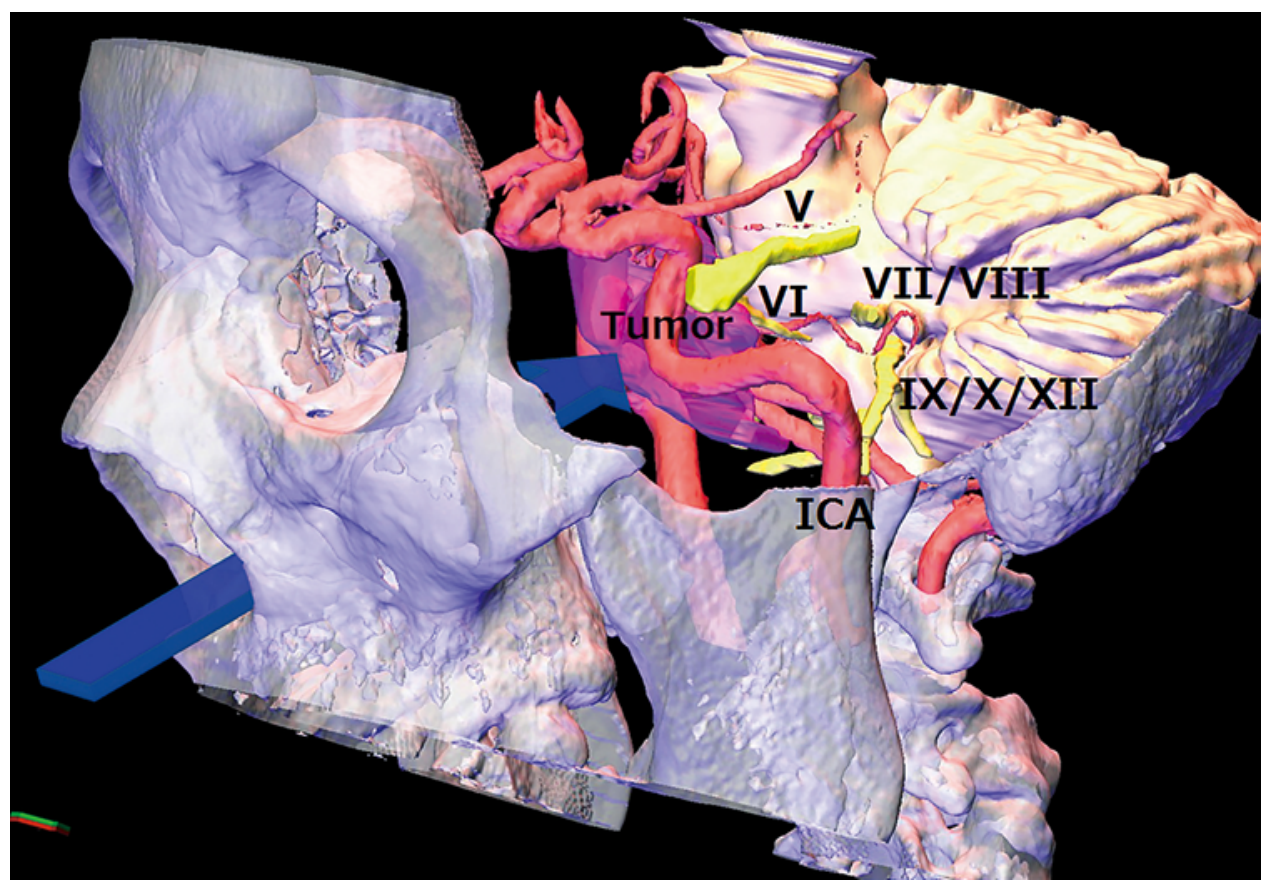

FIG. 6. A schematic of an endoscopic transnasal trajectory is shown. The tumor is located at the paramedian skull base, displacing $\mathrm{CNs}$ laterally. Therefore, a transnasal trajectory can directly approach the tumor between bilateral ICAs without causing interference with $\mathrm{CNs}$. $\mathrm{VI}=$ abducens nerve; $|\mathrm{X} / \mathrm{X} / \mathrm{X}| \mathrm{I}=$ lower cranial nerves. Figure is available in color online only.

\section{Role of Adjuvant RT}

Based on our results, we insist that the routine addition of extensive RT is unnecessary in most cases of chondrosarcoma. Chondrosarcomas have frequently been reported in part of the outcomes of skull base chordoma because of their similarity to the radiographic findings and contiguity of the anatomical origin. ${ }^{13,16,23,25,40,53,54,66}$ In fact, both of those pathologies share several common clinical features, i.e, they are locally aggressive, destroy the deep skull base, and are resistant to conventional fractionated RT. ${ }^{27,45}$ Despite such similarities, their biological behaviors are largely different. Most skull base chordomas are highly proliferative, and sometimes recurrent immediately after GTR. ${ }^{16,24,50}$ Thus, they are often considered a malignancy, which warrants tumor resection with some extent of surgical margin as well as adjuvant extensive RT for prophylaxis. . $^{3,4,24,31,50}$

On the other hand, the significance of adjuvant extensive RT has not yet been determined for skull base chondrosarcoma. The histological diagnosis of chondrosarcoma varies from benign to malignant, and approximately $90 \%$ of the lesions located in the skull base are classified as Grade I or II, showing relatively benign clinical courses. ${ }^{38,48}$ Nonetheless, according to recent clinical reports, extensive RT tended to be systematically added regardless of histological grading and EOR. $., 31,38,44,49,63$ We wonder if the automatic application of the treatment policy obtained from the experience of skull base chordoma is legitimate for the "possibly malignant" but mostly benign skull base chondrosarcoma.

Among a variety of RTs for chondrosarcoma, the efficacy of SRS has been well reported in several previous studies. ${ }^{32,34,37,39}$ Tumor control was excellent when a rela- tively high radiosurgical dose ( $\geq 15-16$ Gy) was prescribed to the margin of small residual tumor. ${ }^{34,39}$ The authors of these previous studies concluded that maximal safe resection should be the primary initial management of chondrosarcoma, whereas SRS is a potent treatment option for small- to medium-sized chondrosarcomas and is associated with improvement of $\mathrm{CN}$ function in selected cases. In our strategy, SRS was added to limited areas only when it was considered appropriate, instead of using extensive RT. The actual rate of the patients who underwent SRS was $21 \%$, and none suffered from radiation-induced complications. Thus, our strategy could contribute to minimizing the non-negligible risks of extensive radiation in certain patients, ,914,26,30,43,49,52,58,61,64 and hold promise of becoming the standard treatment strategy for skull base chondrosarcoma.

\section{Conclusions}

To definitively determine the efficacy of our strategy, further analysis based on the larger case series with a longer follow-up duration is essential. In addition, we could not determine the outcomes of aggressive subtypes (Grade III or mesenchymal type) because the current cohort included only 1 patient with such aggressive chondrosarcoma $(5.3 \%)$. However, our preliminary results suggest that our treatment strategy for skull base chondrosarcoma is rational as an initial treatment policy for chondrosarcoma and may possibly help to establish evidence in the management of these intractable skull base tumors.

\section{References}

1. Abhinav K, Acosta Y, Wang WH, Bonilla LR, Koutourousiou 
M, Wang E, et al: Endoscopic endonasal approach to the optic canal: anatomic considerations and surgical relevance. Neurosurgery 11 (Suppl 3):431-446, 2015

2. Aigner T, Dertinger S, Belke J, Kirchner T: Chondrocytic cell differentiation in clear cell chondrosarcoma. Hum Pathol 27:1301-1305, 1996

3. al-Mefty O, Borba LA: Skull base chordomas: a management challenge. J Neurosurg 86:182-189, 1997

4. Almefty K, Pravdenkova S, Colli BO, Al-Mefty O, Gokden M: Chordoma and chondrosarcoma: similar, but quite different, skull base tumors. Cancer 110:2457-2467, 2007

5. Arbolay OL, González JG, González RH, Gálvez YH: Extended endoscopic endonasal approach to the skull base. Minim Invasive Neurosurg 52:114-118, 2009

6. Austin-Seymour M, Munzenrider J, Goitein M, Verhey L, Urie M, Gentry R, et al: Fractionated proton radiation therapy of chordoma and low-grade chondrosarcoma of the base of the skull. J Neurosurg 70:13-17, 1989

7. Bloch OG, Jian BJ, Yang I, Han SJ, Aranda D, Ahn BJ, et al: A systematic review of intracranial chondrosarcoma and survival. J Clin Neurosci 16:1547-1551, 2009

8. Bloch OG, Jian BJ, Yang I, Han SJ, Aranda D, Ahn BJ, et al: Cranial chondrosarcoma and recurrence. Skull Base 20:149156,2010

9. Bowyer J, Natha S, Marsh I, Foy P: Visual complications of proton beam therapy for clival chordoma. Eye (Lond) 17:318-323, 2003

10. Brackmann DE, Teufert KB: Chondrosarcoma of the skull base: long-term follow-up. Otol Neurotol 27:981-991, 2006

11. Cavallo LM, de Divitiis O, Aydin S, Messina A, Esposito F, Iaconetta G, et al: Extended endoscopic endonasal transsphenoidal approach to the suprasellar area: anatomic considerations-part 1. Neurosurgery 61 (3 Suppl):24-34, 2007

12. Cavallo LM, Messina A, Gardner P, Esposito F, Kassam AB, Cappabianca P, et al: Extended endoscopic endonasal approach to the pterygopalatine fossa: anatomical study and clinical considerations. Neurosurg Focus 19(1):E5, 2005

13. Ceylan S, Koc K, Anik I: Extended endoscopic approaches for midline skull-base lesions. Neurosurg Rev 32:309-319, 2009

14. Chacko JG, Schatz NJ, Glaser JS: Delayed optic nerve complications after proton beam irradiation. Ann Ophthalmol (Skokie) 40:166-170, 2008

15. Chatrath P, Nouraei SA, De Cordova J, Patel M, Saleh HA: Endonasal endoscopic approach to the petrous apex: an image-guided quantitative anatomical study. Clin Otolaryngol 32:255-260, 2007

16. Cho YH, Kim JH, Khang SK, Lee JK, Kim CJ: Chordomas and chondrosarcomas of the skull base: comparative analysis of clinical results in 30 patients. Neurosurg Rev 31:35-43, 2008

17. Colak A, Berker M, Saglam S, Onol B: Chondrosarcoma of the temporal bone in an infant: case report and review of the literature. Neurosurgery 31:956-957, 1992

18. Coltrera MD, Googe PB, Harrist TJ, Hyams VJ, Schiller AL, Goodman ML: Chondrosarcoma of the temporal bone. Diagnosis and treatment of 13 cases and review of the literature. Cancer 58:2689-2696, 1986

19. Crockard HA, Cheeseman A, Steel T, Revesz T, Holton JL, Plowman N, et al: A multidisciplinary team approach to skull base chondrosarcomas. J Neurosurg 95:184-189, 2001

20. d'Avella E, Angileri F, de Notaris M, Enseñat J, Stagno V, Cavallo LM, et al: Extended endoscopic endonasal transclival approach to the ventrolateral brainstem and related cisternal spaces: anatomical study. Neurosurg Rev 37:253260, 2014

21. de Divitiis E: Extended endoscopic endonasal approach. J Neurosurg 116:688, 2012 (Letter)

22. Feng K, Qiuhang Z, Wei Z, Jiabin L, Yukui W, Ge C, et al:
Anatomy of the petrous apex as related to the endoscopic endonasal approach. J Clin Neurosci 19:1695-1698, 2012

23. Frank G, Sciarretta V, Calbucci F, Farneti G, Mazzatenta D, Pasquini E: The endoscopic transnasal transsphenoidal approach for the treatment of cranial base chordomas and chondrosarcomas. Neurosurgery 59:ONS50-ONS57, 2006

24. Fraser JF, Nyquist GG, Moore N, Anand VK, Schwartz TH: Endoscopic endonasal transclival resection of chordomas: operative technique, clinical outcome, and review of the literature. J Neurosurg 112:1061-1069, 2010

25. Gay E, Sekhar LN, Rubinstein E, Wright DC, Sen C, Janecka IP, et al: Chordomas and chondrosarcomas of the cranial base: results and follow-up of 60 patients. Neurosurgery 36:887-897, 1995

26. Habrand IL, Austin-Seymour M, Birnbaum S, Wray S, Carroll R, Munzenrider J, et al: Neurovisual outcome following proton radiation therapy. Int J Radiat Oncol Biol Phys 16:1601-1606, 1989

27. Harwood AR, Krajbich JI, Fornasier VL: Radiotherapy of chondrosarcoma of bone. Cancer 45:2769-2777, 1980

28. Hofstetter CP, Singh A, Anand VK, Kacker A, Schwartz TH: The endoscopic, endonasal, transmaxillary transpterygoid approach to the pterygopalatine fossa, infratemporal fossa, petrous apex, and the Meckel cave. J Neurosurg 113:967-974, 2010

29. Hosseini SM, Razfar A, Carrau RL, Prevedello DM, Fernandez-Miranda J, Zanation A, et al: Endonasal transpterygoid approach to the infratemporal fossa: correlation of endoscopic and multiplanar CT anatomy. Head Neck 34:313-320, 2012

30. Hug EB: Review of skull base chordomas: prognostic factors and long-term results of proton-beam radiotherapy. Neurosurg Focus 10(3):E11, 2001

31. Hug EB, Loredo LN, Slater JD, DeVries A, Grove RI, Schaefer RA, et al: Proton radiation therapy for chordomas and chondrosarcomas of the skull base. J Neurosurg 91:432 439, 1999

32. Iyer A, Kano H, Kondziolka D, Liu X, Niranjan A, Flickinger JC, et al: Stereotactic radiosurgery for intracranial chondrosarcoma. J Neurooncol 108:535-542, 2012

33. Jaberoo MC, Hassan A, Pulido MA, Saleh HA: Endoscopic endonasal approaches to management of cholesterol granuloma of the petrous apex. Skull Base 20:375-379, 2010

34. Kano H, Sheehan J, Sneed PK, McBride HL, Young B, Duma $\mathrm{C}$, et al: Skull base chondrosarcoma radiosurgery: report of the North American Gamma Knife Consortium. J Neurosurg 123:1268-1275, 2015

35. Kassam AB, Gardner P, Snyderman C, Mintz A, Carrau R: Expanded endonasal approach: fully endoscopic, completely transnasal approach to the middle third of the clivus, petrous bone, middle cranial fossa, and infratemporal fossa. Neurosurg Focus 19(1):E6, 2005

36. Kassam AB, Prevedello DM, Carrau RL, Snyderman CH, Gardner P, Osawa S, et al: The front door to Meckel's cave: an anteromedial corridor via expanded endoscopic endonasal approach- technical considerations and clinical series. Neurosurgery 64 (3 Suppl):ons71-ons73, 2009

37. Kim JH, Jung HH, Chang JH, Chang JW, Park YG, Chang WS: Gamma Knife surgery for intracranial chordoma and chondrosarcoma: radiosurgical perspectives and treatment outcomes. J Neurosurg 121 Suppl:188-197, 2014

38. Koch BB, Karnell LH, Hoffman HT, Apostolakis LW, Robinson RA, Zhen W, et al: National cancer database report on chondrosarcoma of the head and neck. Head Neck 22:408425,2000

39. Koga T, Shin M, Saito N: Treatment with high marginal dose is mandatory to achieve long-term control of skull base chordomas and chondrosarcomas by means of stereotactic radiosurgery. J Neurooncol 98:233-238, 2010 
40. Krishnan S, Foote RL, Brown PD, Pollock BE, Link MJ, Garces YI: Radiosurgery for cranial base chordomas and chondrosarcomas. Neurosurgery 56:777-784, 2005

41. McLaughlin N, Kelly DF, Prevedello DM, Shahlaie K, Carrau RL, Kassam AB: Endoscopic endonasal management of recurrent petrous apex cholesterol granuloma. J Neurol Surg B Skull Base 73:190-196, 2012

42. Mesquita Filho PM, Ditzel Filho LF, Prevedello DM, Martinez CA, Fiore ME, Dolci RL, et al: Endoscopic endonasal surgical management of chondrosarcomas with cerebellopontine angle extension. Neurosurg Focus 37(4):E13, 2014

43. Meyers CA, Geara F, Wong PF, Morrison WH: Neurocognitive effects of therapeutic irradiation for base of skull tumors. Int J Radiat Oncol Biol Phys 46:51-55, 2000

44. Moussazadeh N, Kulwin C, Anand VK, Ting JY, Gamss C, Iorgulescu JB, et al: Endoscopic endonasal resection of skull base chondrosarcomas: technique and early results. J Neurosurg 122:735-742, 2015

45. Neff B, Sataloff RT, Storey L, Hawkshaw M, Spiegel JR: Chondrosarcoma of the skull base. Laryngoscope 112:134139, 2002

46. Osawa S, Rhoton AL Jr, Seker A, Shimizu S, Fujii K, Kassam AB: Microsurgical and endoscopic anatomy of the vidian canal. Neurosurgery 64 (5 Suppl 2):385-412, 2009

47. Paluzzi A, Gardner P, Fernandez-Miranda JC, Pinheiro-Neto CD, Scopel TF, Koutourousiou M, et al: Endoscopic endonasal approach to cholesterol granulomas of the petrous apex: a series of 17 patients: clinical article. J Neurosurg 116:792798, 2012

48. Rosenberg AE, Nielsen GP, Keel SB, Renard LG, Fitzek MM, Munzenrider JE, et al: Chondrosarcoma of the base of the skull: a clinicopathologic study of 200 cases with emphasis on its distinction from chordoma. Am J Surg Pathol 23:1370-1378, 1999

49. Sahgal A, Chan MW, Atenafu EG, Masson-Cote L, Bahl G, Yu E, et al: Image-guided, intensity-modulated radiation therapy (IG-IMRT) for skull base chordoma and chondrosarcoma: preliminary outcomes. Neuro Oncol 17:889-894, 2015

50. Samii A, Gerganov VM, Herold C, Hayashi N, Naka T, Mirzayan MJ, et al: Chordomas of the skull base: surgical management and outcome. J Neurosurg 107:319-324, 2007

51. Sbaihat A, Bacciu A, Pasanisi E, Sanna M: Skull base chondrosarcomas: surgical treatment and results. Ann Otol Rhinol Laryngol 122:763-770, 2013

52. Schlampp I, Karger CP, Jäkel O, Scholz M, Didinger B, Nikoghosyan A, et al: Temporal lobe reactions after radiotherapy with carbon ions: incidence and estimation of the relative biological effectiveness by the local effect model. Int J Radiat Oncol Biol Phys 80:815-823, 2011

53. Sekhar LN, Pranatartiharan R, Chanda A, Wright DC: Chordomas and chondrosarcomas of the skull base: results and complications of surgical management. Neurosurg Focus 10(3):E2, 2001

54. Sen CN, Sekhar LN, Schramm VL, Janecka IP: Chordoma and chondrosarcoma of the cranial base: an 8-year experience. Neurosurgery 25:931-941, 1989

55. Shin M, Kondo K, Kin T, Suzukawa K, Saito N: Endoscopic transnasal interseptal approach for invasive clival tumors: development of an approach method regarding maximal preservation of the nasal anatomy. Neurol Med Chir (Tokyo) 55:336-344, 2015

56. Shin M, Kondo K, Hanakita S, Hasegawa H, Yoshino M, Teranishi Y, et al: Endoscopic transsphenoidal anterior petrosal approach for locally aggressive tumors involving the internal auditory canal, jugular fossa, and cavernous sinus. J Neurosurg 126:212-221, 2017

57. Shin M, Kondo K, Saito N: Neuroendoscopic transnasal surgery for skull base tumors: basic approaches, avoidance of pitfalls, and recent innovations. Neurol Med Chir (Tokyo) 52:697-703, 2012

58. Slater JD, Austin-Seymour M, Munzenrider J, Birnbaum S, Carroll R, Klibanski A, et al: Endocrine function following high dose proton therapy for tumors of the upper clivus. Int J Radiat Oncol Biol Phys 15:607-611, 1988

59. Taniguchi M, Akutsu N, Mizukawa K, Kohta M, Kimura H, Kohmura E: Endoscopic endonasal translacerum approach to the inferior petrous apex. J Neurosurg 124:1032-1038, 2016

60. Taniguchi M, Kohmura E: Endoscopic endonasal removal of laterally extended clival chordoma using side-viewing scopes. Acta Neurochir (Wien) 154:627-632, 2012

61. Tzortzidis F, Elahi F, Wright DC, Temkin N, Natarajan SK, Sekhar LN: Patient outcome at long-term follow-up after aggressive microsurgical resection of cranial base chondrosarcomas. Neurosurgery 58:1090-1098, 2006

62. van Swieten JC, Koudstaal PJ, Visser MC, Schouten HJ, van Gijn J: Interobserver agreement for the assessment of handicap in stroke patients. Stroke 19:604-607, 1988

63. Weber DC, Badiyan S, Malyapa R, Albertini F, Bolsi A, Lomax AJ, et al: Long-term outcomes and prognostic factors of skull-base chondrosarcoma patients treated with pencil-beam scanning proton therapy at the Paul Scherrer Institute. Neuro Oncol 18:236-243, 2016

64. Weber DC, Malyapa R, Albertini F, Bolsi A, Kliebsch U, Walser M, et al: Long term outcomes of patients with skullbase low-grade chondrosarcoma and chordoma patients treated with pencil beam scanning proton therapy. Radiother Oncol 120:169-174, 2016

65. Zanation AM, Snyderman CH, Carrau RL, Gardner PA, Prevedello DM, Kassam AB: Endoscopic endonasal surgery for petrous apex lesions. Laryngoscope 119:19-25, 2009

66. Zhang Q, Kong F, Yan B, Ni Z, Liu H: Endoscopic endonasal surgery for clival chordoma and chondrosarcoma. ORL J Otorhinolaryngol Relat Spec 70:124-129, 2008

\section{Disclosures}

The authors report no conflict of interest concerning the materials or methods used in this study or the findings specified in this paper.

\section{Author Contributions}

Conception and design: Shin, Hasegawa. Acquisition of data: Hasegawa, Kondo, Hanakita, Kin. Analysis and interpretation of data: Hasegawa. Drafting the article: Hasegawa. Critically revising the article: Shin, Saito. Reviewed submitted version of manuscript: Shin, Kondo, Hanakita, Mukasa, Kin, Saito. Approved the final version of the manuscript on behalf of all authors: Shin. Statistical analysis: Hasegawa. Administrative/technical/material support: Kin. Study supervision: Shin, Mukasa, Saito.

\section{Correspondence}

Masahiro Shin, Department of Neurosurgery, University of Tokyo Hospital, 7-3-1 Hongo, Bunkyo-ku, Tokyo 113-8655, Japan. email: shin-nsu@h.u-tokyo.ac.jp. 